\title{
Digital transformation in financial services provision: A Nigerian perspective to the adoption of chatbot
}

Purpose: Recognising the high numbers of unbanked and financially excluded adults in Nigeria, this study positions chatbot as a digital transformation tool to radically change business model, improve customer experience, and enhance financial inclusion in emerging markets.

Methodology: The Search-Access-Test (S-A-T) model was adopted to understand how Nigerian banks are adopting chatbots.

Findings: Majority of Nigerian banks now have chatbots which enhance customer engagement and financial inclusion. WhatsApp was the most frequently used platform. Chatbots were often branded and presented with female gender identification. The chatbots were less responsive beyond their pre-defined path. While Nigeria is a multilingual country with English being the original language, none of the chatbots used any of the Nigerian's local languages.

Originality: While many theoretically based model for investigating the adoption of digital technologies has often placed focus on users' ability to engage, this study takes an alternative perspective; by using the Search-Access-Test (S-A-T) model, it lays the responsibilities on the banks and chatbot developer to ensure that their chatbots are secure, responsive and able to meet the needs of the customers.

Practical implications: Brands needs to reevaluate their chatbots with regards to responsiveness, pre-defined questions, verification and privacy. There are also possibilities of branding the chatbot and developing content creation strategies for proper engagement. Beyond English, the integration of African languages into chatbot is essential for digital transformation. Digital literacy and skills, particularly in the field of science, technology, engineering and mathematics (STEM) should be supported to equip future developers and create more jobs.

Keywords: Digital Transformation; Chatbot; Financial Inclusion; Nigeria; Emerging Markets; Banks 


\section{Introduction}

Emerging technologies are challenging existing business practices and altering firm-customer relationships (Setia, et al., 2013; Vial, 2019). Digital transformation represents the evolving changes in society and businesses using digital technologies (Majchrzak, et al., 2016) to enhance major business improvements, improving customer experience and creating new business models (Fitzgerald, et al., 2014; Piccinini, et al., 2015). Vial (2019) summarily described the digital transformation as "a process that aims to improve an entity by triggering significant changes to its properties through combinations of information, computing, communication, and connectivity technologies".

This description recognises the prospects of digital transformation to trigger significant changes in how businesses operate by combining different forms of technologies. It is therefore not surprising to see the modus operandi of many companies to change since the advent of technology especially the introduction of digitisation which has brought about new fronts at which businesses are being operated (Setia, et al., 2013). Acknowledging the organisations' capabilities to leverages digital capabilities and technologies to change their business model to meet the changing consumer behaviour and needs (Li, et al., 2018). This suggests why digital transformation through technology has been considered inherently disruptive (Karimi \& Walter, 2015; Vial, 2019).

This disruption is even more evident in financial services provision where banks are changing from the traditional methods which are less effective and efficient to a modern and more effective means of delivering their services to their target markets (Mogaji \& Danbury, 2017). Banks can use chatbots to provide 24 hours of service to meet the unending needs of 21 stcentury consumers (Carbo-Valverde, 2017). In the work of Abbasi and Weigand (2017) it 
shows the role information and communication technologies (ICT) played in assisting the financial sector, especially commercial banks, in boosting their banking services.

With a specific focus on emerging markets in Africa, digital transformation in financial services presents opportunities to a change in the business model for economic and social growth, financial inclusion for those who are unbanked and enhance the customer experience. Highlight the vast possibilities of using information and communications technologies (ICTs) to address socio-economic issues such as access to formal financial services (David-West, et al., 2019). Financial services are hugely necessary to the functioning of our economy. The financial markets connect savers and investors through the investment chain; helping the rest of the economy manage risk, and to provide the necessary payment systems and mechanisms to store value needed for trade to take place. Financial services are utilitarian service, as that money is required to support people's daily activities, and its benefits are essential to both individual and corporate consumers (Albers-Miller \& Stafford, 1999), importantly in an emerging market where access to funds is crucial, financial services play an essential role. This study, therefore, aims to explore chatbots as digital transformation tool, which supports emerging markets' drive towards financial inclusion and financial services provisions. Particularly, the paper offers an understanding of how these chatbots have been developed and positioned by banks to meet the need of the customers in an Africa's emerging market - Nigeria.

The contextualisation of this study in Nigeria is particularly worthwhile for several reasons. Firstly, Nigeria is the most populated country in Africa, with a population of over 200 million, accounting for about $16 \%$ of the total population of the continent. Secondly, the country is an economic power, as the World Bank (2019) reported that Nigeria is the second-largest economy in the continent after South Africa. Thirdly, despite being a huge economy, many people in the country are still unbanked. And as such, it could be argued for a digital transformation that can bring financial inclusion, i.e. engaging the many unbanked into the 
banking system. According to The Global Findex Database, $60 \%$ of Nigerian adults have are unbanked as they do not have an account with a financial institution or a mobile money provider (Demirgüç-Kunt, et al., 2018). Nigeria and six other countries contribute nearly half of the globe's unbanked adult population of 1.7 billion, and $56 \%$ of that figure are women. Fourthly, since Nigeria is an emerging economy, which is facing institutional adversity and underlying and persistent economic challenges (Mogaji, 2020), the task of meeting the financial needs of this enormous population presents challenges. However, These challenges highlight a huge prospect of adopting chatbot as a digital transformation tool to aid consumer engagement with financial services; and ultimately this utilisation of chatbot can deliver significant business gains and increased access for consumers (Fitzgerald, Kruschwitz, Bonnet, \& Welch, 2013). Finally, compared to its African counterparts, Nigeria has a more developed and relatively well-capitalised banking system characterised by strong banking profits and some of the continent's most profitable banks (African Business, 2019), this banking system, therefore, is in a better position pursue innovative banking practices (Allen, et al., 2011).

For the above reasons, Nigeria represents a relevant and meaningful context to examine digital transformation, particularly one of its tools - chatbot, in the financial services industry, to advance theoretical development and maintain relevance in practice. This current situation of sizable unbanked population illustrates the growing need for Nigerian banks to be more responsive and contribute towards the economic development of the country, especially through digital transformation. Digital transformation is relatively a new as the world is at the doorstep of the fourth industrial revolution, and what adds to further deficiencies in the extant literature is that most research and practices of digital transformation have been implemented in developed markets. To fill this perceived gap, this study draws on the frugal theory of innovation (Bhatti, 2012) and a novel methodology - Search-Access-Test methodological framework, which combines case study research, content analysis and user testing. Such 
research design enables the survey to make a pivotal contribution to the literature on digital transformation, digital inclusion and financial services in emerging markets. First, it extends the knowledge of how banks in an emerging market are using chatbots to engage and enable financial inclusion through their digital transformation initiatives. Second, it establishes the concept of digital transformation in emerging economies, with specific focus on financial services. Third, this study contributes to literature on the challenges and barriers to digital transformation in Africa's emerging markets. Importantly, this study highlights the role of chatbot for financial inclusion, in which it can enhance human capital and capacity building of the citizen, unlock barriers to financial services and encourage digital inclusion for economic stability. Lastly, the study offers managerial implications for bank managers, digital transformation developers and policymakers.

The rest of this paper is organised as follows. The next section reviews the literature on the concept of digital transformation, chatbot and financial inclusion. Then it is followed by the methodology section that highlights the searching for existing chatbot by banks, accessing them and testing their responsiveness. The results section will discuss the concept of these chatbots, operating platforms and responsiveness. The paper is concluded with acknowledging limitations and suggesting avenues for further research.

\section{Literature Review}

\section{Digital Transformation in Africa}

The fact that digital transformation is going on in Africa cannot be denied. Ndemo \& Weiss (2017) noted that digital technologies are spreading fast across the African continent as the total sub-Saharan ICT Market is expected to grow from $\$ 95.4 \mathrm{bn}$ in 2020 to reach $\$ 104.2 \mathrm{bn}$ by 2023 (Walker, 2020), This potential for growth was further corroborated by G7's communique on digital transformation in Africa which acknowledge that such transformation could be a 
game-changer for the African continent with the prospect of economic growth, poverty alleviation and financial inclusion $(\mathrm{G} 7,2019)$. It was suggested that the use emerging digital transformation which recognises the role of big data/analytics, social media, and mobility (Walker, 2020) would contribute to the African Union Agenda 2063 (G7, 2019).

Ndemo \& Weiss (2017) developed a framework of Africa's emerging digital transformation, and they elaborated on the multiple environments that digital technologies have influenced and shaped. Digital transformation in Africa has covered manufacturing with automated sales processing; government using AI for citizen's service delivery; eCommerce disruption in retails and integrated patients record in healthcare provision (Walker, 2020), however financial services transformation has taken for the front in Africa (Ndemo \& Weiss, 2017). The digital transformation can trace its history to the invention of mobile banking which was introduced by some telecommunication companies such as Safaricom in Kenya, which happens to be a subsidiary of British group Vodafone, and this was carried out through a system known as MPesa system, and this swiftly overtook the conventional banking methods. Africa had been one of the continents with very poorly banked people, having an average of banking rate of 5 to $15 \%$ among African countries, except for the Maghreb region and South Africa. Telecommunication companies have utilised and leverage on their proximity to customers and availability of mobile terminals, whether with common basic phones features making it possible to use Unstructured Supplementary Service Data (USSD) protocol or the popular smartphones, to offer a wide range of mobile banking services (Wayne, et al., 2020).

The increase in mobile phone subscriber numbers and access to the internet has extensively contributed to digital transformation in Africa (Ndemo \& Weiss, 2017). Mhlungu, et al. (2019) noted that customer-centricity, governance, innovation and resource attainment as factors that will shape a successful integration of digital transformation initiative. Walker (2020) however suggested that relevance of the solution, financial capabilities to afford the transformation, 
security and accessibility, especially with regards to the internet are key pillars for digital transformation in Africa. With regards to internet access,

Specifically, in Africa emerging markets, some challenges inhibit digital transformation. First, the recognition of technology is low, many companies and countries have yet to embrace the possibilities of technologies fully and it is not surprising to see that many countries are still struggling with policies to drive financial services through the of technology (David-West, et al., 2019),

Secondly, as many people may have to use the internet to access these technologies, poor internet connection poses a problem. The internet penetration in Nigeria stood at $42 \%$ in January 2020, and the average speed of mobile internet connections in Nigeria is $15.32 \mathrm{Mbps}$ compared to the United Kingdom with 35.57 Mbps and Australia with 67.66 and with $96 \%$ of mobile connections in Nigeria being prepaid (DataReportal, 2020). Countries in emerging economies also have an average speed of $10 \mathrm{Mpbs}$ (Hannato, 2019). While much progress has been made with global connectivity, there are notable gaps in terrestrial access across the continent, especially in rural and semi-rural areas (Walker, 2020).

Also, the power supply in these countries possesses a challenge which may affect the adoption of digital transformation technologies. The World Energy Outlook special report recognises the persistent lack of access to electricity and the unreliability of electricity supply in emerging countries, including Africa. This lack of access is a factor inhibiting the progress and development of the continent as there are over 600 million people who do not have access to electricity in Africa (IEA, 2019). While the continent has $20 \%$ of the world's population, it accounts for less than $4 \%$ of global electricity use (Economist, 2019). Despite these challenges and limitation, Digital transformation in Africa is rapidly growing (van Dyk \& Van Belle, 2019). 
Digital Disruption is expected to keep growing in Africa (Ndemo \& Weiss, 2017), innovations are emerging from startups with unique business models that aimed to bridge an existing gap in the market (Bett, 2018), more established organisations are also taking responsibilities to innovate, transforming their business practises and directing their innovation efforts at bringing more people into their fold. It is, however, essential for manages to identify and overcome challenges before they occur (Walker, 2020).

\section{Chatbots for Digital Transformation}

A Chatbot is a representative of an individual, group of individuals or organisation (s) that is designed in human-like nature that has the potentials and ability to attend and respond immediately to organisational customers request made in different forms either oral, written or the combination of both (Hatwar et al., 2016). The chatbot was coined from the popular word "ROBOT" which means a device can stand in place of human being and do precisely what they among which is to chat (Patil \& Kulkarni, 2019). They are designed to adapt to different languages its users can make use of which makes it easier to use in different parts of the world and also by a different class of people. This is made possible through designing chatbots in Natural Language Processing or Artificial Intelligence Markup Language (Khanna et al., 2015).

The chatbot can be seen as a robotic virtual conversational agent, which can interact and exchange voice and text messages with one or more simultaneous users via a computer network. Considering the idea that the extent to which the customer finds it easy to access an appropriate person and/or facility is regarded as a critical customer experience quality (Lemke, et al., 2011), chatbot plays a crucial role, always at hand to offer help, and to assist consumers. They are described this as a never-sleeping, cost-efficient, and powerful way to provide basic 
support to the consumer (Alleycat, 2017) and this highlights the prospects it offers for transformation in Africa.

Chatbots are faster at giving real-time responses to customers (Methew, 2016), they can personalise consumer experiences as they can understand the patterns of their interactions with customers, making consumers feel that they are being treated in a personal manner. Chatbots are also able to collect customer data from support interactions and adjust themselves accordingly (Alleycat, 2017). Consumers engage with healthcare chatbots like Your.MD and Babylon which asks users to provide information about their symptoms and the chatbot can help identify the problem, provide relevant and trusted health information and advice on the next step to take. Within retails, Consumers can engage with Echo from Amazon. In the hospitality sector, Taco Bell also created Tacobot, an artificial-intelligence-powered ordering service which allows consumers to order food and customise their meals by chatting with the chatbot. These highlights the huge role chatbot plays in building an emotional experienced with the customer as they engage with the service providers. Likewise, for many unbanked and financially excluded people, access to this chatbot makes them closer to the Bank, coupled the advancement in machine parsing and understanding spoken or typed requests (Quoc, 2016), there are possibilities of integrating seamless opportunities to enhance consumers' experience through interaction.

Despite these prospected, chatbots are being challenged by serious exposure to web attacks which continue to pose challenges to its effective utilisation (Kaushik, Agrawal \& Rahman, 2015). Also, there are growing concerns about privacy and data control and management, questioning how the big data generated through these chat are being managed (Dwivedi, 2019). The human resources needed to develop and integrate the chatbot as a digital transformation tool also present an additional challenge for its adoption and use (Shum, et al., 2018; Dwivedi, 2019) 


\section{Digital Transformation for Financial inclusion}

The digitalisation of financial services provides a different perspective on how banking services are being provided and delivered to satisfy their customers. Technology has changed businesses and within-business connections. These changes have resulted in the reconfiguration of product design, changes in marketing programs, production, method of delivery and services through supply chains, more independent structure, and many others. A study carried out by Gareth et al. (2016) as used by Abbasi and Weigand (2017) showed that some banks in the developed worlds such as North America, Europe, Asia- Pacific and Latin America invest a total amount of $\$ 241$ billion on digitalisation of their banking process in the year 2016 and this was increased by almost $4 \%$ when compared with the investment made on it in the year 2015.

Recognising financial inclusion as the provision of verifiable and affordable products (financial services) that bring customers of different social class into the same structured and formal banking system (United Nations, 2016), utilising formal and structured bank services by customers who happens to belong to the less privileged or low-income earner categories (Beck, Demirgu“c-Kunt, \& Levine, 2007; Bruhn \& Love, 2014), Digital technologies present opportunities to bridge the gap between the banks and the unbanked financially excluded customers (Mogaji, et al., 2020).

David-West et al. (2019) acknowledged the role of technology in African financial services provided as an intersection of social innovation, technological innovation, and institutional innovation. This highlights the prospects, albeit under-explored value of chatbot for financial inclusion which will spur economic and social growth of the continent. With financial services industry and mobile telephony making so much progress (David-West, et al., 2019), Artificial 
intelligence in the form of chatbot become relevant as a digital transformation tool (Ndemo \& Weiss, 2017 (Dwivedi, 2019) for digital financial services that can enhance financial inclusion which can assist in developing the lives of citizens and the country as a whole (Beck et al., 2007; Bruhn \&Love, 2014).

While previous studies on digital transformation in financial studies have a focus on mobile money (David-West, et al., 2019; Adeleye, et al., 2019), Chatbots is one of the newly developed and adopted platform through which commercial banks can adopt in bringing the vast populace of unbanked individuals (Dwivedi, 2019) especially the continuous increase in the number of smartphones users which can serve as an advantage in making known the process which will assist in increasing their customer base and market share.

\section{Theoretical Framework}

Many theoretically based and contextual model for investigating the adoption of digital technologies has been developed, but often they are from users' perspectives (Mogaji et al. 2020). The responsibility has usually been placed on the user to derive gratifications from using the technologies while the role of the developer in making the innovation accessible is seldom overlooked. This study takes an alternative perspective to the technology adoption concepts by laying the responsibilities on the banks and chatbot developer to ensure that their chatbots are secure, responsive and able to meet the needs of the customers.

To achieve this, we adopt the frugal theory of innovation, which propose the desire to make a transformational change lies within the intersection of technology, social and institutional innovations (Bhatti, 2012). Specifically, Bhatti (2012) further noted that frugal innovation redefines business models, redesign products and services in a way to create more inclusive markets. This is not only limited to businesses but also relevant for non-government organisations and government organisations (Hossain, 2017). From a digital transformation 
perspective, this theory has been applied in understanding sustainable development (Rosca, et al., 2018), Hospital transportation (Sahay \& Walsham, 2017) and manufacturing networks (Mourtzis, et al., 2019). From an African emerging market perspective, David-West, et al. (2019) adopted this theory to explore Mobile money as an innovation for the bottom of the pyramid in selected African countries. Peša (2015) explored frugal innovation and local economic development in Zambia, while Malik (2017) theoretically examined the unique capabilities of emerging-market multinational enterprises.

From a chatbot context as digital innovation, the frugal theory of innovation recognises the technology innovation developed by banks to engage with customers and bring financial services closer to them (Wayne, et al., 2020), likewise, the social innovation here highlights the need for financial inclusion through an affordable and easy to use digital technology (David-West, et al., 2019), this social innovation expresses a creative and innovative approach to meet the social need for financial inclusion. (Bhatti, 2012). While the institution innovations recognise the policy in place to support financial inclusion, this represents the responsibilities placed on the banks by the government and policymakers to ensure financial inclusion (Adeleye, et al., 2019). As illustrated in the theoretical framework in Figure 1, these intersections of innovations are placed on the banks to develop digital innovation, which is a chatbot on this case, to engage with customers and support the drive for financial inclusion through the provision of accessible financial services and products. It is anticipated that this innovation will create value for underserved markets (Bhatti, 2012). 


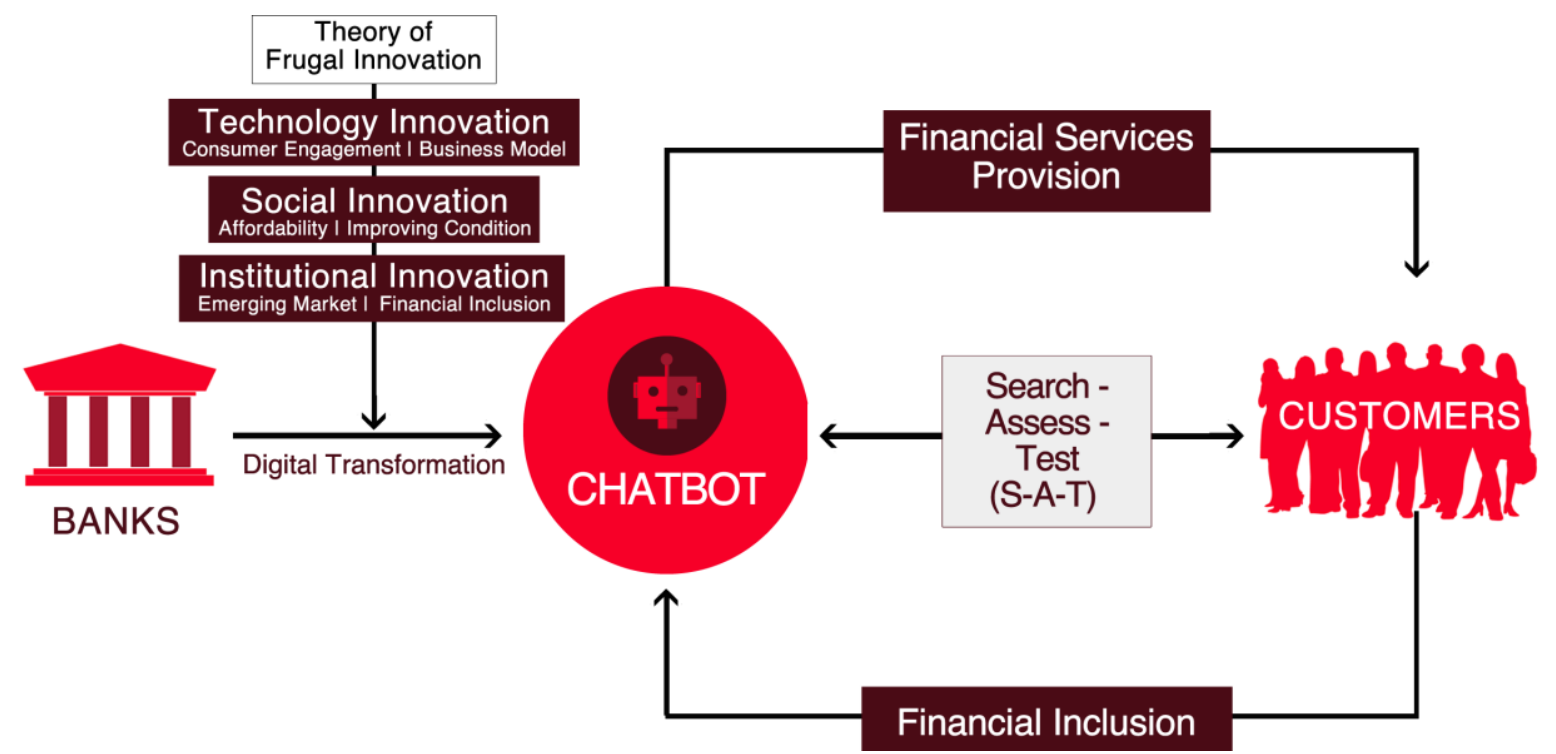

Figure 1: Theoretical Framework for Chatbot as Digital Transformation for Financial Inclusion

To theoretically examine these innovations through the chatbot design and development, a novel theoretical and methodological approach is adopted. The Seach-Assess-Test (S-A-T) framework explores the chatbot with the specific intention of understanding the effort the banks has put into designing it to ensure financial inclusion. This methodological build son the ALARA model of information search (Mogaji, 2019) which expects information custodians to make the information available, easily accessible and relatable. Also, the methodological approach builds on the Marchionini (1995) effort to recognise the various interactions between the entities of the searcher, the information needs and environmental local of the information. In this study, it is anticipated that Nigerian commercial banks will have chatbot as a digital transformation tool (Search) and these chatbots will have the essential features to support the transformation (Assess) and these features will be tested to establish how responsive they are in meeting the needs of the users (Test). The methodological approach is discussed in the subsequent section. 


\section{Methodology}

\section{Commercial Banks Adoption of Chatbots in Nigeria}

Nigeria's financial institutions are taking a new turn, and this can be accounted for by the intervention of financial technology (FinTech). The adoption of FinTech has significantly assisted commercial banks in many ways, from effective utilisation of resources to reduction in costs, to reduction time of handling complaints, and to reaching a larger population of customers. Today's customers value their time and want their financial transactions, either online or offline, to be done swiftly without lengthy waiting. The decreases in data costs and prices of phones, especially smartphones, in Nigeria, has contributed to the growing numbers of users. Since people have turned those platforms into channels where conversations including financial matters, can take place, Nigerian commercial banks started seeing the need for adopting new ways to deliver their services, making those more accessible and easier to use.

\section{Search-Access-Test (S-A-T) model}

This study adopts a novel research methodology, the Search-Access-Test (S-A-T) model which takes up the role of an information searcher and incorporates the idea of netnography and user experience design ( (Mogaji, et al., 2020). This is an inductive approach which starts with the researcher collecting data, followed by taking a step backwards to have a general review of the collected data, identifying patterns, and after that developing a theory from the observed patterns (Blackstone; 2012). This approach allows the possibilities of using participants' views, in this case, the prospective user of the chatbot, to build broader themes and generate a theory interconnecting the themes (Creswell and Plano Clark, 2007). This S-A-T approach highlights the availability of chatbot by the banks, provision of information and engaging user-interface for the prospective bank customers who may want to use it. Like the ALARA Model of Information Search (Mogaji, 2019), responsibility is placed on the Bank to make their chatbot 
accessible and engaging. The methodology enhances understanding of digitally occurring interactions and experiences on chatbot (Mogaji, 2019). Three key stages are outlined in using this method. These stages are discussed in subsequent subsections.

\section{Search}

This study was conducted in all commercial banks that were operational in Nigeria in 2020 . According to the Central Bank of Nigeria $(\mathrm{CBN}), 22$ commercial banks are active in Nigeria (CBN, 2020). The first step was to search for the chatbots that have been developed by the banks. Initial searches were carried out online through Google search for 'Nigerian bank's chatbot'. This search revealed three chatbots (from UBA, Access and FCMB).

Further search was carried out on the other Bank's website to establish if there is a mention of a chatbot on the site. Social media of the banks were also checked to ensure that at the 22 banks were represented. News Briefings were also searched in case there was a press release to introduce a new chatbot. Contacts of the authors were also asked to confirm the available chatbots. After an exhaustible search, it was found that some banks still did not have a chatbot. So as not to conclude that they do not have, emails and Direct messages were sent to the banks to confirm, of which they did confirm they do not have a chatbot.

\section{Analysis}

Each of these chatbots was analysed to understand better how they have been developed to encourage financial inclusion and customer engagement. The analysis stage involves the use of content analysis. A coding sheet was created for each Bank's chatbot that was identified in the initial search in Stage 1. The coding sheet is considered an essential feature of content analysis studies, often developed to facilitate data collection and analysis (Mogaji, 2018). The chatbots were analysed based on their devices ( $1=$ mobile, $2=$ computer $)$, the platform on which they operate ( $1=$ Facebook, $2=$ Telegram, $3=$ WhatsApp), In addition to the analysis, we explored 
if the chatbot has been customised and given an identity/name ( $0=$ Not customised, 1=Customized), For those chatbots that have been customised, our analysis further explored the gender of the chatbot. In most cases, these chatbots are either male or female and often presented with a cartoon character profile/image ( $0=$ Unknown, $1=$ Female, $2=$ Male). To evaluate security concerns, we explored the verification status of these chatbots $(0=$ Not verified, $1=$ Verified). A coding

\section{Testing}

Each of these chatbots were further tested ad used to understand better how they work. In some cases, the WhatsApp numbers of the banks were saved on a mobile phone and were automatically connected through WhatsApp. In some instances, Telegram was also used. For Keystone Bank, prospective users were expected to download and install "Keystone Mobile" from the Google Play or App store before using the chatbot on Instagram. Upon launching the chatbot, testing involves exploring the provision of terms and condition. This was considered essential for the consumer to be aware of these terms and condition before using the chatbot. Following that, the language options were considered. In a country with over 500 languages (WorldAtlas, 2020), it is anticipated that the chatbot will support digital inclusion by using multiple languages, allowing consumers to conduct banking transactions using their language without being restricted to the country's official language, i.e. English (Wayne et al., 2020). Following on from the language, we explored the options provided by the chatbots and the feedback. For example, when we selected the ATM location, it was expected to provide ask for our address and then offer the closest ATM. The summary of the Search-Access-Test model is presented in Table 1 below. 


\begin{tabular}{|c|c|c|}
\hline Search & Access & Testing \\
\hline - Banks, Website & - Device & - Responsiveness \\
\hline - Social Media & - Platform & - Terms and Condition \\
\hline - Advertisements & - Customisation & - Language \\
\hline - News Briefing & - Verification & - Options \\
\hline - Emails & - Gender & - Feedback \\
\hline
\end{tabular}

Table 1: Summary of the Search-Access-Test model

A content analysis following the described coding sheet in Stage 2 was carried out online using Google Form. Krippendorf (1980, p. 21) describes it as a "research technique for making replicable and valid inferences from the data regarding their contexts" while Kassarjian (1977) believed it is the best method for providing a "scientific, quantitative, and generalisable description of communications content" (p. 10). Considering only 16 chatbots were being analysed, one of the authors solely carried out the analysis.

Several steps were carried to ensure the credibility of the analysis; first, the Google Form (available at shorturl.at/kqv35) was used to ensure that the research data collection and result are readily available and open for researcher and any other person interested in verifying the data. Second, another author carried out the analysis again using a different google form. The intercoder reliability was after that calculated. Neuendorf (2002, p. 141) argued that "without the establishment of reliability, content analysis measures are useless". This is considered an integral part of the content analysis (Mogaji, 2018). The intercoder reliability between both coders was 1.0. This perfect intercoder reliability testifies to the high quality of coding which is considered acceptable, and that the chatbots were analysed consistently. Third, audit trails were kept and shared between the team. Following Lincoln and Guba (1985, p. 125) proposed an idea for ensuring transferability, a thick description of the research process was kept. Fourth, 
the researcher meets for debriefing sessions as it offered the opportunity to discuss the results, recognising biases and ensure objective reporting. Fifth, we also acknowledge that the background, qualifications, and experience of the researcher also contribute towards the trustworthiness of the research (Shenton, 2004) as the researcher plays a prominent role in collecting and analysing the data (Patton, 2015).

\section{Result}

The extensive search of banks using chatbots in Nigeria revealed that only thirteen (59\%) of the twenty-two banks had a form of a chatbot for consumer engagement and financial transactions. The banks that the research could not find their chatbots were contacted for further insights. Some of the big banks like Zenith Bank did not have a chatbot. Still, they referred the researchers to chat with a customer service representative on their websites, which is defeated by the response of chatbot that is more responsive and always present. Older banks like Wema Bank claimed that their chatbot on WhatsApp was currently unavailable and newer banks like Globus Bank, which have promised a truly digital commercial Bank leveraging technology to deliver engaging customer experience, did not have a chatbot but claimed that it is a work-inprogress.

For the thirteen banks with chatbots, there were cases with banks having more than one chatbot on different platforms. Therefore, the total number of chatbots found and analysed was sixteen. Access Bank, Fidelity and Keystone have two each. Access Bank had their chatbots on its website and WhatsApp. Fidelity had theirs on both Facebook Messengers and WhatsApp, while Keystone had theirs on Facebook Messenger and Telegram. Excluding Access Bank's chatbot on the website, the remaining fifteen chatbots were on mobile messaging applications. $53.3 \%(n=8)$ of the chatbots were on WhatsApp, 33.3.\% $(n=5)$ were on Facebook while 13.35( $\mathrm{n}=2)$ were on Telegram. 
The majority of the chatbots were customised and had a unique identity. $68 \%(n=11)$ of them had a name which they use during the conversations. These chatbots started their conversation by mentioning their names. Also, during the marketing and brand integration of the chatbots, their names have often been mentioned by the banks. The customised identities are Leo (UBA), Rafiki (Ecobank), Sami (Stanbic IBTC), Oxygen (Keystone Bank), Temi (FCMB), Ivy (fidelity Bank), Octopus (Heritage Bank) and Tamada (Access Bank). These chatbots' icons were designed and illustrated to engage with the customers in a way that the chatbots are given a narrative. The customisation also came with gender appropriation as well. Seven of the icons were assigned a gender. $42.2 \%(n=6)$ were presented as females while only one, Leo from UBA was a male.

To further access the security and data privacy measures of these digital transformation tools, the verification signs and provision of terms and condition were evaluated. Only $33.3 \%(n=5)$ of the chatbots were verified, and they were all on WhatsApp. There was no verification sign on Facebook Messenger and Telegram. This highlight a safety concern and the need to reassure the users that they are engaging with the official and authentic chatbot. Besides, $25 \%(n=4)$ of the chatbots provided terms and condition of use before allowing users. The users had to accept these terms before proceeding. It is anticipated that consumers will be reminded that their chat may be recorded for training, quality control and dispute handling purposes. Users were also warned not to share any sensitive information in the chatbox unless specifically asked.

While Nigeria is a multilingual country with English being the original language, none of the chatbots used any of the Nigerian's local languages. It is expected that some people may be discouraged from using these chatbots because of language barriers. $84.6 \%(n=11)$ used only English in the conversation, while two chatbots - Leo from UBA and Rafiki from Ecobank offered English and other foreign languages (like French and Spanish). 
The chatbots can support customers with opening an account which further supports the drive for financial inclusion, and Users are also able to send money, pay bills and manage their profiles. In some cases, the chatbot can also answer some personal finance questions. In most cases, to fully benefit from the features of the chatbots, the banks are requesting for a phone number, especially on WhatsApp, Bank Verification Number, Account Numbers and other personal details. This was, however, different from Fidelity Bank and Access Bank, which allowed those with no phone number can also benefit from what the chatbot has to offer. Both were asked for ATM locations, and it provided. The rate of response was, however, different among these chatbots.

The responsive nature of the chatbots was also tested during the third stage of the S-A-T model. Messages (starting with 'hello' or 'hi') were sent to the chatbot, and 50\% (n=8) responded instantly, 31.3\% $(n=5)$ had a delayed response while 18.8\% $(n=3)$ did not respond at all. They were irresponsive and did not reply to the message. This irresponsiveness again defeats the acceptance of chatbot since as customers often anticipate an instant reply from their chatbot.

Considering NLP is an integral part of chatbots, the manner of introduction and engagement were observed, and three chatbots stood out. All were on Facebook, and they were customised with female gender appropriation. They started the conversation by introducing themselves to the customers. It appeared natural, just like the agent is meeting the customer in person. 


\section{Stanbic IBTC Sami}

Hello, [customer's name]! $\odot$

My name is Sami.

I can help you check your Stanbic IBTC bank balance, help you send money to your friends, buy airtime or pay bills. I can also answer some personal finance questions.

I'm still in beta so I might not have all the answers, but I'm sure I can assist.

\section{EcoBank Rafiki}

Hi [customer's name], Welcome to Ecobank. I am Rafiki, I can help you begin to receive payments with Ecobank Pay; Open Xpress account; Send money; Buy airtime; Get Account Balance; Check Rates and Mini statement.

\section{FCMB Temi}

[Starting with an illustrated/cartoon profile picture]

Good Afternoon [customer's name],

My name is Temi. I'm your banker and I work with First City Monument Bank.

What would you like to do today?

For those chatbots with a delayed response, two factors were observed. Firstly, they were being managed by people, and it was not surprising that they did not respond immediately. Unity Bank responded after seven minutes with a reassuring messaged that 'Na human being dey here, [This is human here] And we are available to assist always'. Secondly, an automated 
message was presented as the banks were suggesting the impact of Covid-19 pandemic. Union Bank apologised that their time to respond to enquiries may take longer than usual as they were adjusting to Covid-19 realities. They pleaded customers to bear with them and that an agent would be available shortly. However, it had taken fifty-one minutes until a human agent replied with the willingness to help.

The responsiveness was also examined in terms of the questions being asked. In most cases, the chatbot as preset questions; and in some cases, users were to select numerical digits ([1] Payday Loan Issue, [2] Transaction (WEB / POS) by Access Bank) or alphabetical letters (A. My Balance, B. Airtime Topup from Fidelity), and once these questions are selected, they would respond accordingly. This, however, was not the case for some chatbots when a different question was asked. As illustrated in Figure 2, when FCMB Temi was asked about ATM locations, the female-gendered chatbot could not respond, whereas Fidelity Bank's Ivy was able to process that information and offered the locations of ATMs

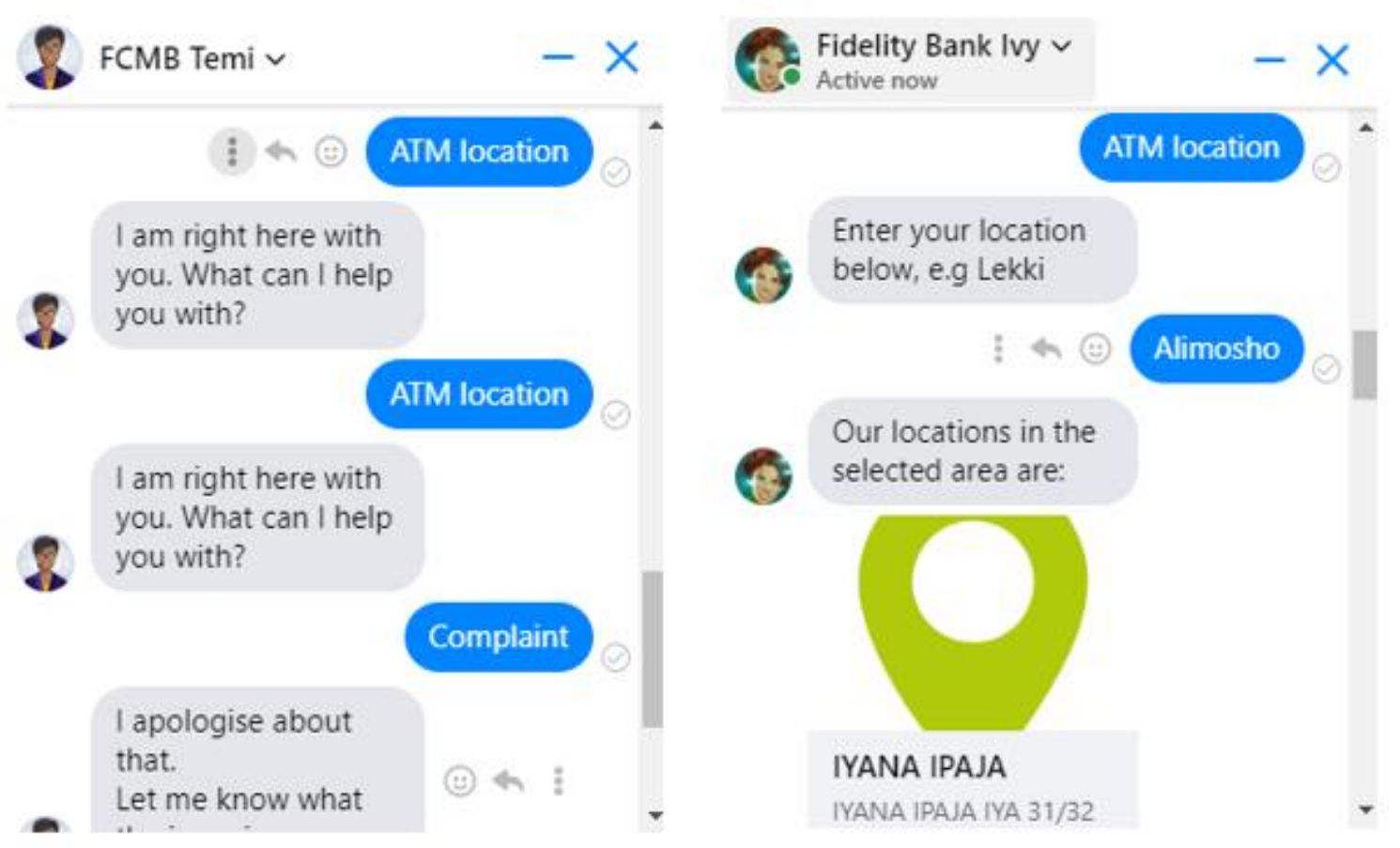

Figure 2: Interaction with FCMB Temi and Fidelity Bank Ivy 


\section{Discussions}

This study has considered the adoption of chatbots as a digital transformation tool for financial services inclusion and engagement. The chatbots have been provided by banks to receive information from the customers concerning their account and financial transactions. Chatbot brings financial services closers to the consumers, allowing them to engage with their banks, with the anticipation that the involvement in financial services will drive the economic and social growth of the community.

The adoption of this digital transformation tool has been explored within the banking system of the second biggest economy in Africa where most of these banks have adopted chatbots, and there are possibilities that many more will adopt it. The results highlight the prospects of this tool for its development within the continent.

Even with this growing trend and prospects, key challenges and barriers to this digital transformation have been identified. Among with is the responsiveness with regards to response time, the human connection to take over from the chatbot and engagement beyond the pre-defined path set by the chatbot developer (Debecker, 2017). Also, there were challenges with language options. The fact that all the chatbots were predominantly in English, even as local languages have been considered useful for chatbots and natural language dialogue systems (AbuShawar \& Atwell, 2016) and considering chatbots should be able to respond to various queries at any time in different languages and across different platforms, which is beyond human customer service assistants' capabilities (Alleycat, 2017), there are huge implications on integrating African languages in digital transformation in Africa. None of these chatbots has any African language such as Swahili, Yoruba or Afrikaans. 
This study contributes to the digital transformation literature in many ways. First, it extends our knowledge on how banks in an emerging market are using a chatbot to engage and enable financial inclusion through their digital transformation initiatives. The chatbot allows consumers to open a bank account, apply for loans and carry out financial transactions without getting to the Bank. Second, it provides a theoretical understanding from an emerging country's perspective. Recognising the inherent challenges and barriers to digital transformation in Africa's emerging markets like electricity and internet connection, measures are being developed to engage with the consumers. Third, the methodological approach offers a unique perspective to this understanding, not just an analysis of what is happening but testing the chatbots to provide more holistic views and experience of using this transformational technology.

There are also implications for data collection and processing through the chatbots, considering that most of the chatbots do not have terms and conditions; it is essential to understand the ethical implications of digital transformation. There is an ethical question concerning whether consumers' data will be harvested without their consent, all for the sake of benefitting from digital transformation. There are also concerns around the accuracy, suitability, reliability, completeness, performance, the fitness of these digital tools. The research also emphasises the need to identify who takes responsibility for this digital transformation implementation. Would it be the brands, the governments or third parties such as developers? Can these tools be legally and ethically used for advice and decision-making? Do the developers absorb themselves such liabilities? These ethical questions and concerns are critical for emerging markets where policies and procedures may not be duly followed and observed.

The empirical results from this study also provide important managerial implications for managers, digital technology developers and other stakeholders. First, the study provides an overview of one of the digital technologies - chatbot - presently in use in the Nigerian banking 
industry, and what can be done to improve its use and adoption. For brands having more than one mobile application, they may want to focus on one application, possibly WhatsApp as a more user-friendly platform. For those with no verification, it may be essential to seek verification of their chatbot to reassure consumers of their safety when they engage with the chatbot. Also, those with no terms and conditions, it will be necessary to consider including those before consumers use the chatbot for the first time. This is to reassure the consumers that their information is securely protected.

Second, there are also implications for the design and user interface of the chatbot. As some chatbot did not reply, the responsiveness and the content of the chatbot should also be improved. Consumers want an instant reply from their chatbot. Considering that the extent to which the customer finds it easy to access chatbot can be regarded as a key customer experience quality (Lemke, et al., 2011), the organisation needs to improve the responsiveness of their chatbots. Also, recognising that some of the chatbots have names (Leo from UBA and Tamada from Access), there are possibilities for branded features and content creation and engaging narrative around these characters. UBA's Leo was an excellent example, as illustrated in Figure 3.
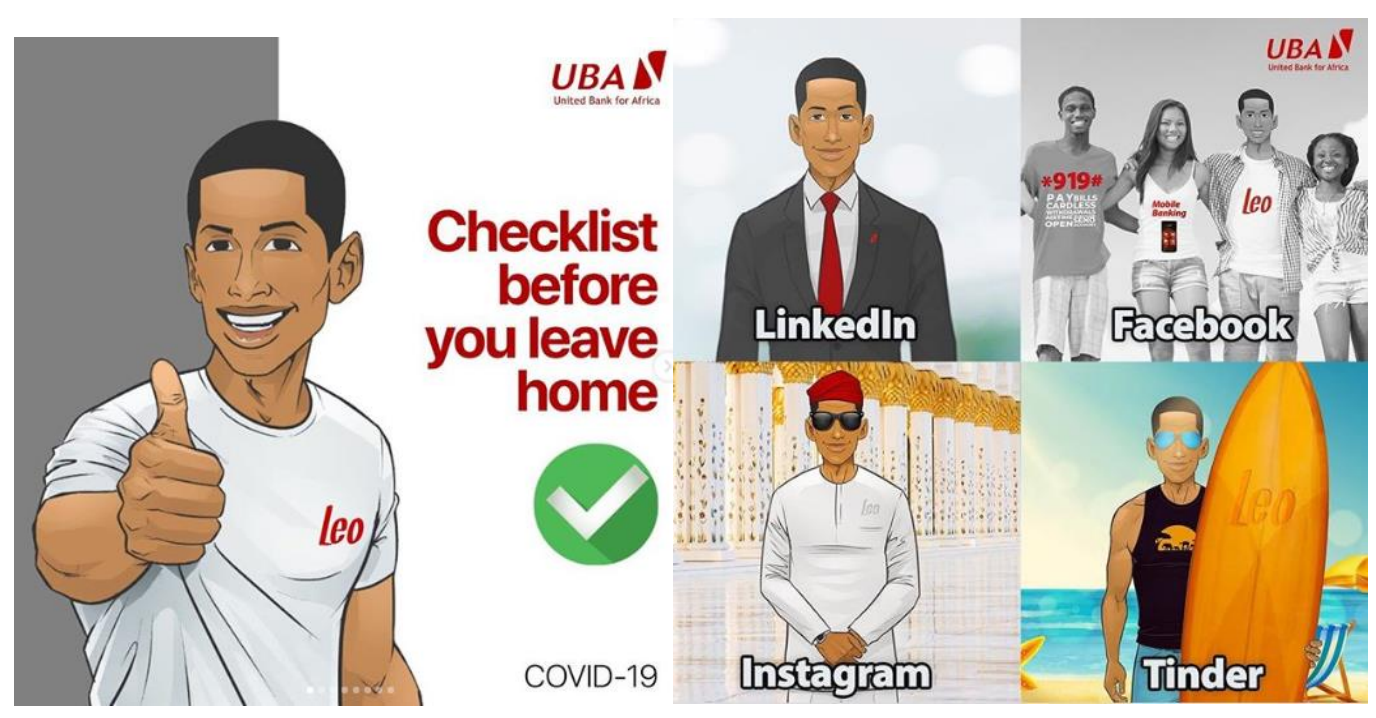

Figure 3: UBA Leo in different forms. Source: UBA Instagram page. 
Third, it is also essential for banks to raise awareness about this digital transformation tool. Recognising the prospects of a chatbot for enhancing financial inclusion and reaching the unbanked, the banks need to communicate the values of this digital transformation technology, educating the consumers about what it can do and be used for, and reassuring them of their security. Developing a digital transformation strategy is not sufficient for improving governance, economic growth, and inclusion (World Bank, 2019), communicating and engaging with stakeholders is paramount.

Fourth, there are implications for the skills needed to develop digital transformation in Africa. In the case of the chatbots, this will allow more banks and organisations to integrate chatbot as part of their digital transformation strategy. It will improve the users' experience in terms of interface design and responsiveness, as well as it will support the adoption of Africa languages into chatbots ensuring that we have chatbots that can engage in Yoruba or Igbo language. There are needs for universities to offer courses in artificial intelligence and machine learning, providing the enabling environment for people to learn and develop their skills. Digital literacy and skills, particularly in the field of science, technology, engineering and mathematics (STEM) should be supported to equip future developers and create more jobs.

Fifth, recognising that there are growing support and facilitation of digital transformation in Africa; many sectors will start to consider adopting chatbot as a digital transformation tool, this study, therefore, presents a relevant insight that can be adapted for other industries and sector. This may be retail stores, healthcare professionals and educational institutions. The study provides practical guides for effective adoption of the chatbot.

Lastly, this study also provides relevant insights for industries and organisations in many other emerging markets. Learning from how Nigerian banks have adopted their chatbots provides a reassuring motivation of possibilities Though not being yet perfect, many positive insights can 
be applied in other countries with a less challenging economy, smaller population and human resources. This study has highlighted the use of chatbot as a tool to deliver positive impacts of digital transformation in Africa's emerging markets. By focusing on financial services and the current state of financial exclusion in Nigeria, it highlights how technology can bridge the gap between the unbanked and the banked populations. The underlying challenges of emerging countries, including those concerning privacy and data protection, have been ecognised (elysee.fr, 2019). Notwithstanding, the study highlights a prosperous future, enabled by digital transformation, in the emerging markets and communities of Africa and beyond.

\section{Conclusion}

This study recognises the importance of digital transformation for the social and economic development of a country, with a specific interest in Nigeria. This country is one of the biggest emerging markets and the most populous countries in Africa and has a strong banking sector. This paper illustrates chatbot as a digital transformation tool for financial inclusion and consumer engagement, highlighting its capabilities and prospects to enhance customer satisfaction and increase digital capabilities. The study recognises that although there are inherent challenges like electricity and poor internet connection, this digital technology can still be adapted to meet the needs of the customers.

The S-A-T methodological approach adopted has revealed a better understanding of the physical design elements of these chatbots and how they have been developed to meet the needs of the customers. Findings reflect that most banks are applying chatbot. However, there are differences with regards to the platforms, customisation and the responsiveness of the chatbot. Illustrations and screenshots are presented in the supplementary data file. Our empirical results present both theoretical and managerial implications for bank managers, digital technology developers and policymakers. 
Although the study was carefully designed, conducted, and provided valuable information and insights, this study has limitations which warrant future research. These limitations should be taken into considerations when interpreting the results. First, the results may not be widely generalisable because the study only investigated banks in Nigeria and may not be a true reflection of other emerging markets and communities of Africa. Future research may consider how banks in other countries are using and deploying chatbots. Second, the chatbots were tested in June 2020, and changes could have been made to these chatbots or new chatbots created before the publication of this paper, notwithstanding, an insight into the use of chatbots by Nigerian banks has been unveiled.

\section{References}

AbuShawar, B. \& Atwell, E., 2016. Usefulness, localizability, humanness, and languagebenefit: additional evaluation criteria for natural language dialogue systems. International Journal of Speech Technology, 19(2), pp. 373-383.

Adeleye, I., Debrah, Y. \& Nachum, L., 2019. Management of financial institutions in Africa: Emerging themes and future research agenda. Africa Journal of Management, 5(3), pp. 215230.

African Business, 2019. Special Report: Africa's Top 100 Banks 2019. [Online] Available at: https://africanbusinessmagazine.com/africas-top-100-banks/special-reportafricas-top-100-banks-2019/

[Accessed 55 2020].

Allen, F., Otchere, I. \& Senbet, L. W., 2011. African financial systems: A review. Review of Development Finance, 1(2), pp. 79-113.

Alleycat, C., 2017. The benefits of chatbots in customer service roles. [Online] Available at: https://chatbotslife.com/the-benefits-of-chatbots-in-customer-service-rolesbc6b2c1bf54d

[Accessed 22 2018].

Bett, M. C., 2018. Digital Disruption in the Financial Service Industry: A Case of Afya Sacco in Kenya. Kenya: Doctoral dissertation, United States International University-Africa. 
Bhatti, Y. A., 2012. What is frugal, what is innovation? Towards a theory offrugal innovation, Oxford: Said Business School Working Paper Series.

David-West, O., Iheanachor, N. \& Umukoro, I., 2019. Mobile money as a frugal innovation for the bottom of the pyramid-Cases of selected African countries. Africa Journal of Management, 5(3), pp. 274-302.

Demirgüç-Kunt, A. et al., 2018. The Global Findex Database 2017 Measuring Financial Inclusion and the Fintech Revolution. Washington: International Bank for Reconstruction and Development/The World Bank.

Dwivedi, Y. K. e. a., 2019. Artificial Intelligence (AI): Multidisciplinary perspectives on emerging challenges, opportunities, and agenda for research, practice and policy. International Journal of Information Management, p. https://doi.org/10.1016/j.ijinfomgt.2019.08.002.

Economist, 2019. More than half of sub-Saharan Africans lack access to electricity. [Online] Available at: https://www.economist.com/graphic-detail/2019/11/13/more-than-half-of-sub$\underline{\text { saharan-africans-lack-access-to-electricity }}$

[Accessed 55 2020].

Fitzgerald, M., Kruschwitz, N., Bonnet, D. \& Welch, M., 2014. Embracing digital technology: A new strategic imperative. MIT sloan management review, 55(2), pp. 1-16.

Freeman, R., 2010. Strategic management: A stakeholder approach. 2nd ed. Cambridge: Cambridge University Press.

G7, 2019. Digital Transformation in Africa, Biarritz, France: G7.

Hossain, M., 2017. Mapping the frugal innovation phenomenon. Technology in Society, Volume 51, pp. 199-208.

Hyken, S., 2017. AI And Chatbots Are Transforming The Customer Experience. [Online] Available at: https://www.forbes.com/sites/shephyken/2017/07/15/ai-and-chatbots-aretransforming-the-customer-experience/\#585e4dc041f7

[Accessed 22 2018].

IEA, 2019. Africa Energy Outlook 2019. [Online] Available at: $\quad$ https://www.iea.org/reports/africa-energy-outlook-2019 [Accessed 55 2020]. 
Karimi, J. \& Walter, Z., 2015. The role of dynamic capabilities in responding to digital disruption: A factor-based study of the newspaper industry. Journal of Management Information Systems, 32(1), pp. 39-81.

Lemke, F., Clark, M. \& Wilson, H., 2011. Customer experience quality: an exploration in business and consumer contexts using repertory grid technique. Journal of the Academy of Marketing Science, 39(6), pp. 846-869.

Li, L., Su, F., Zhang, W. \& Mao, J., 2018. Digital transformation by SME entrepreneurs: A capability perspective. Information Systems Journal, 28(6), pp. 1129-1157.

Majchrzak, A., Markus, M. \& Wareham, J., 2016. Designing for digital transformation: Lessons for information systems research from the study of ICT and societal challenges. MIS quarterly, 40(2), pp. 267-277.

Malik, O., 2017. When Davids start becoming Goliaths: unique capabilities of emergingmarket multinational enterprises and how they foster growth in developed markets?. International Journal of Technology Management, 74(1), pp. 45-69.

Methew, A., 2016. How Live Chat can Impact Your Customer Satisfaction. [Online] Available at: http://customerthink.com/how-live-chat-can-impact-your-customer-satisfaction/ [Accessed 22 2018].

Mhlungu, N. S., Chen, J. Y. \& Alkema, P., 2019. The underlying factors of a successful organisational digital transformation. South African Journal of Information Management, 21(1), pp. 1-10.

Mogaji, E., 2019. The ALARA Model of Information Search on Websites. Research Agenda Working Papers, 2019(6), pp. 82-91.

Mogaji, E., 2020. Impact of COVID-19 on transportation in Lagos, Nigeria.. Transportation Research Interdisciplinary Perspectives, Volume July, p. 100154.

Mogaji, E., Anyogu, A. \& Wayne, T., 2020. Minding the Gap: An assessment of the quality of course information available on the websites of African Universities. In: Higher Education Marketing in Africa. Cham: Palgrave Macmillan, pp. 277-314.

Mogaji, E. \& Danbury, A., 2017. Making the brand appealing: advertising strategies and consumers' attitude towards UK retail bank brands. Journal of Product \& Brand Management., 26(6), pp. 531-544. 
Mogaji, E., Soetan, T. O. \& Kieu, T. A., 2020. The implications of artificial intelligence on the digital marketing of financial services to vulnerable customers. Australasian Marketing Journal, Volume https://doi.org/10.1016/j.ausmj.2020.05.003.

Mourtzis, D., Zogopoulos, V. \& Vlachou, K., 2019. Frugal innovation and its application in manufacturing networks. Manufacturing Letters, Volume 20, pp. 27-29.

Ndemo, B. \& Weiss, T., 2017. Making sense of Africa's emerging digital transformation and its many futures. Africa Journal of Management, 3(3/4), pp. 328-347.

Peša, I., 2015. Homegrown or imported? Frugal innovation and local economic development in Zambia. Southern African Journal of Policy and Development, 2(1), pp. 5-20.

Piccinini, E., Hanelt, A., Gregory, R. \& Kolbe, L., 2015. Piccinini, E., Hanelt, A., Gregory, R., \& Kolbe, L. (2015). Transforming industrial business: the impact of digital transformation on automotive organisations.. s.1., ICIS2015.

Quoc, M., 2016. 11 Examples of Conversational Commerce and Chatbots. [Online] Available at: https://chatbotsmagazine.com/11-examples-of-conversational-commerce$\underline{57 \mathrm{bb} 8783 \mathrm{~d} 332}$

[Accessed 22 2018].

Rosca, E., Reedy, J. \& Bendul, J., 2018. Does frugal innovation enable sustainable development? A systematic literature review. The European Journal of Development Research, 30(1), pp. 136-157.

Sahay, S. \& Walsham, G., 2017. Information technology, innovation and human development: hospital information systems in an Indian state. Journal of Human Development and Capabilities, 18(2), pp. 275-292.

Setia, P., Setia, P., Venkatesh, V. \& Joglekar, S., 2013. Leveraging digital technologies: How information quality leads to localised capabilities and customer service performance. Mis Quarterly, 37(2), pp. 565-590.

Shum, H., He, X. \& Li, D., 2018. From Eliza to XiaoIce: challenges and opportunities with social chatbots. Frontiers of Information Technology \& Electronic Engineering, 19(1), pp. 1026.

Singh, A. \& Hess, T., 2017. How Chief Digital Officers promote the digital transformation of their companies. MIS Quarterly Executive, 16(1), pp. 1-17. 
van Dyk, R. \& Van Belle, J. P., 2019. Factors influencing the intended adoption of digital transformation: a South African case study. s.1., IEEE, pp. 519-528.

Vial, G., 2019. Understanding digital transformation: A review and a research agenda. The Journal of Strategic Information Systems, 28(2), pp. 118-144.

Walker, M., 2020. Digital transformation in Africa. [Online] Available at: $\quad$ https://www.bizcommunity.com/Article/196/379/201652.html [Accessed 55 2020].

Wayne, T., Soetan, T., Bajepade, G. \& Mogaji, E., 2020. Technologies for Financial Inclusion in Nigeria. Research Agenda Working Paper, 2020(4), pp. 40-56.

WorldAtlas, 2020. What Languages Are Spoken In Nigeria?. [Online] Available at: https://www.worldatlas.com/articles/what-languages-are-spoken-in-nigeria.html [Accessed 203 2020]. 


\section{Supplementary Data}

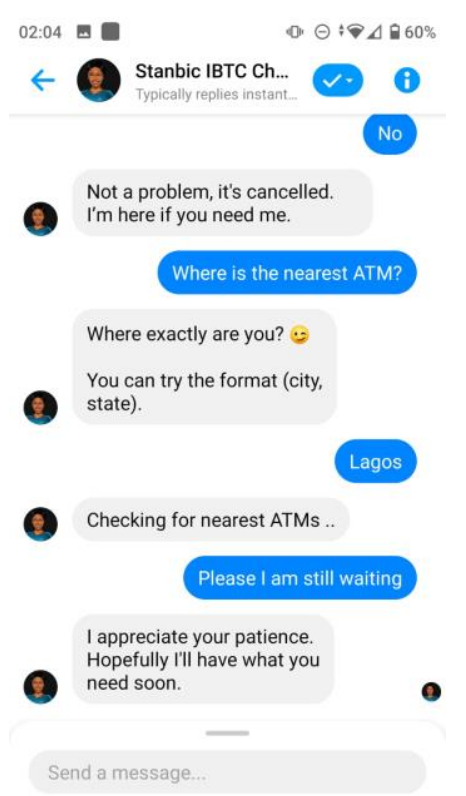

Figure 1: Stanbic IBTC Sami struggling with the ATM location question.
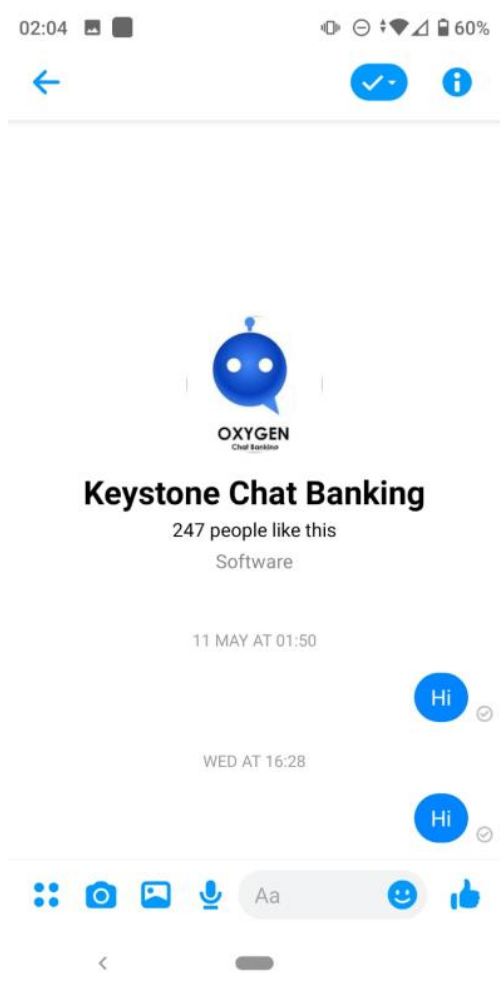

Figure 2: The non-responsive Keystone Oxygen on Facebook Messanger 


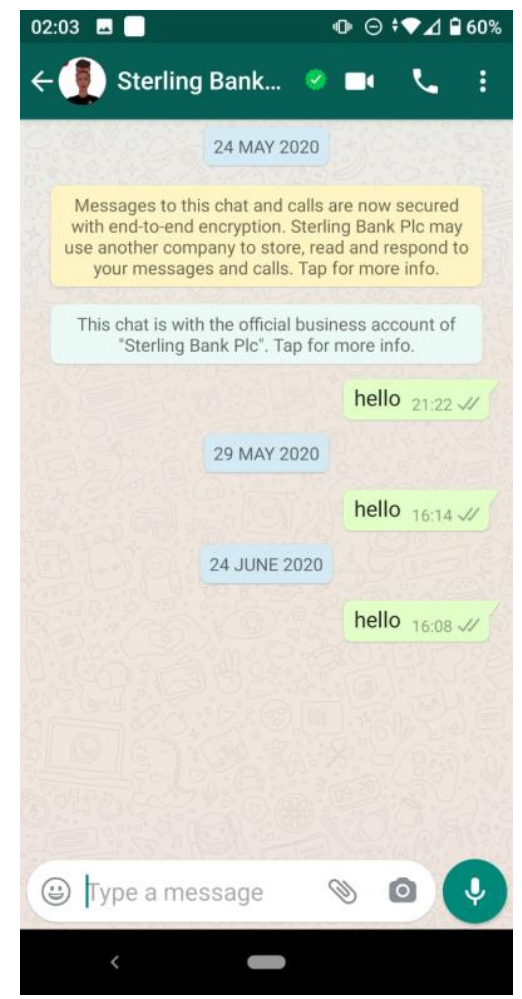

Figure 3: The Non-responsive Sterling Bank Chatbot on WhatsApp. Even though it was verified, it was not active.

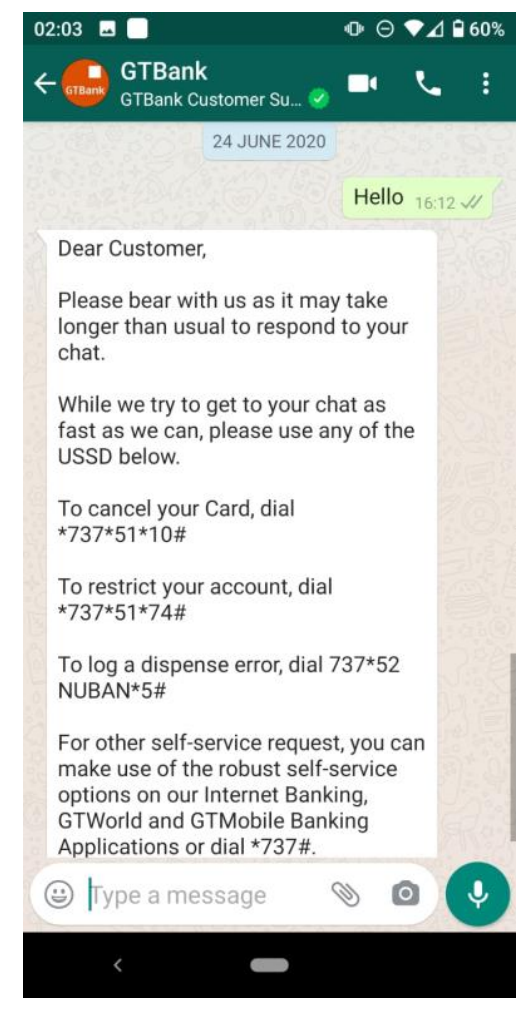

Figure 4: GTB Chatbot on WhatsApp advising that it may take longer than usual to responds. 


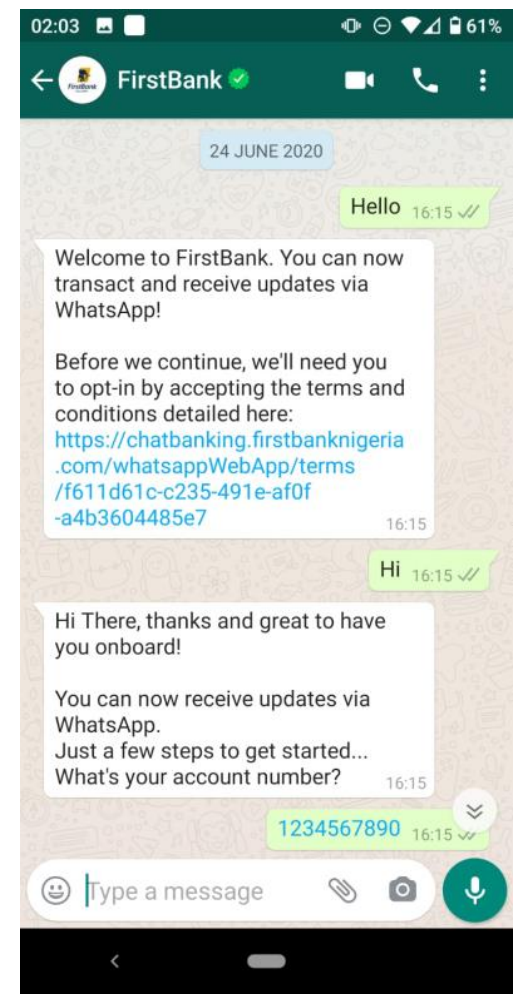

Figure 5: FirstBank Chatbot on WhatsApp, displaying term and condition link

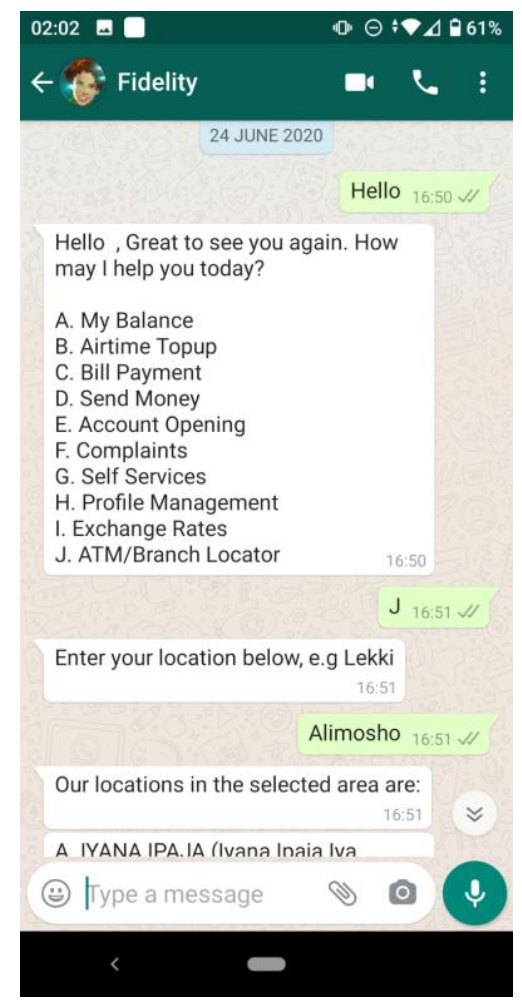

Figure 6: Fidelity Bank’s Chatbot answering the ATM location question. 


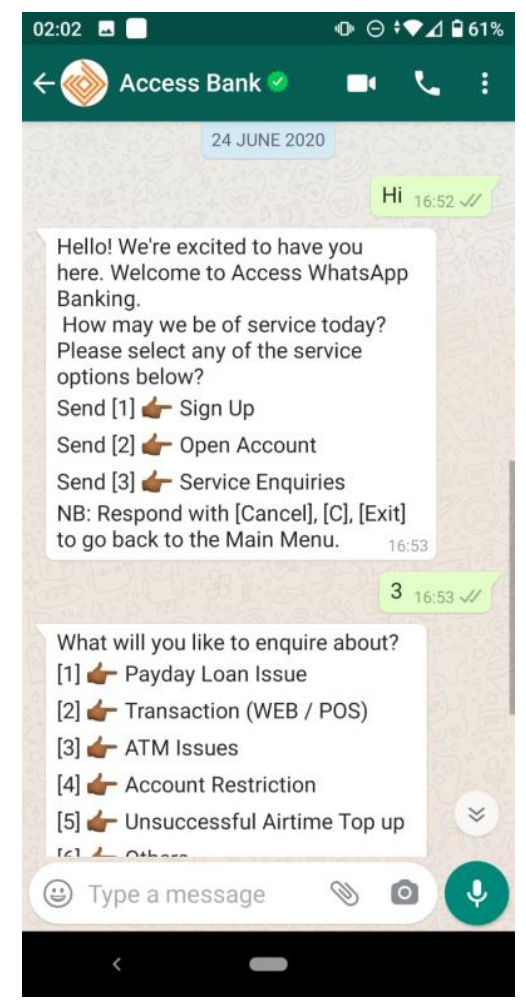

Figure 7: Access Bank Chatbot with options for users

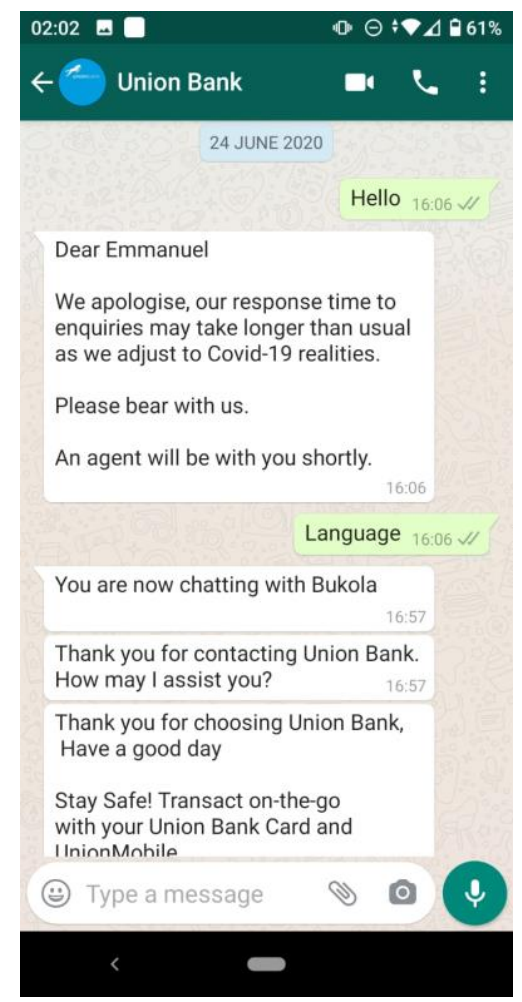

Figure 8: Union Bank's Chatbot with both human and chatbot response. The automated reply acknowledging they are adjusting to COVID-19 realities, but human agent subsequently joined the conversation 


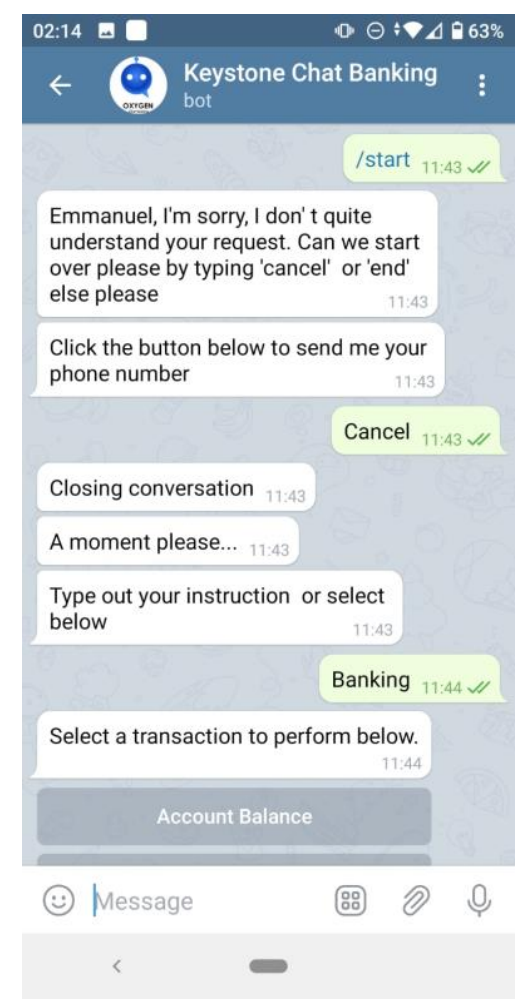

Figure 9: Keystone Bank's Oxygen on Telegram. This was very responsive unlike the Facebook messenger (Figure 2)

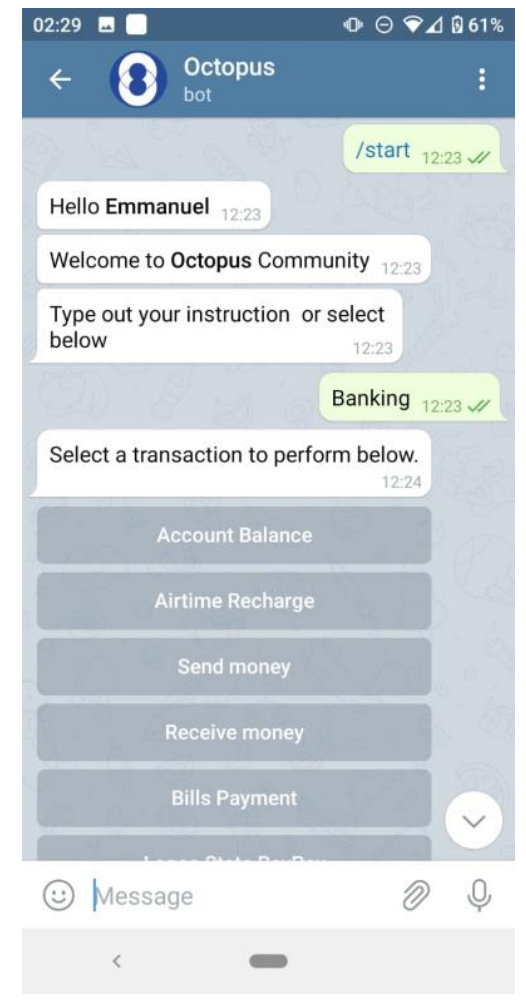

Figure 10: Response Octopus Chatbot on Telegram from Heritage Bank 


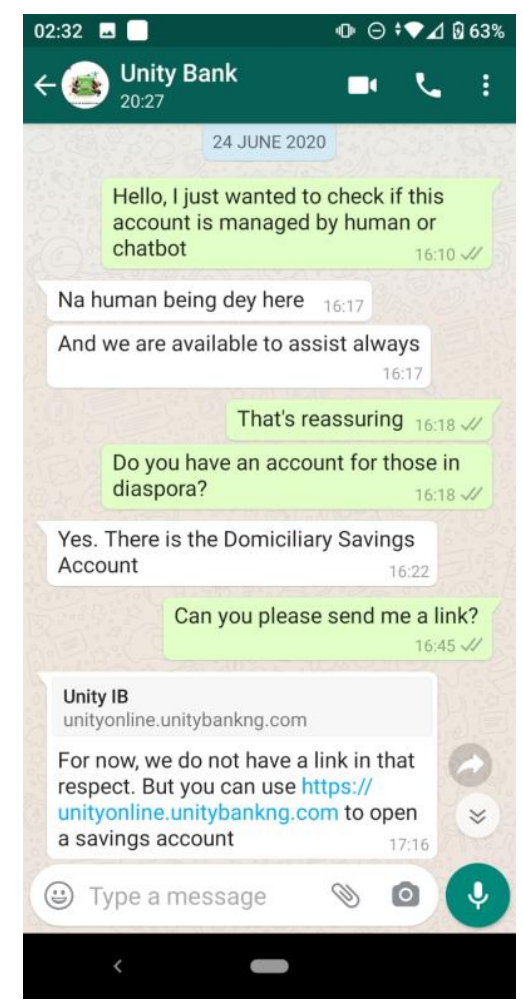

Figure 11: Chatbot from Unity Bank which is not controlled by a robot but by human.

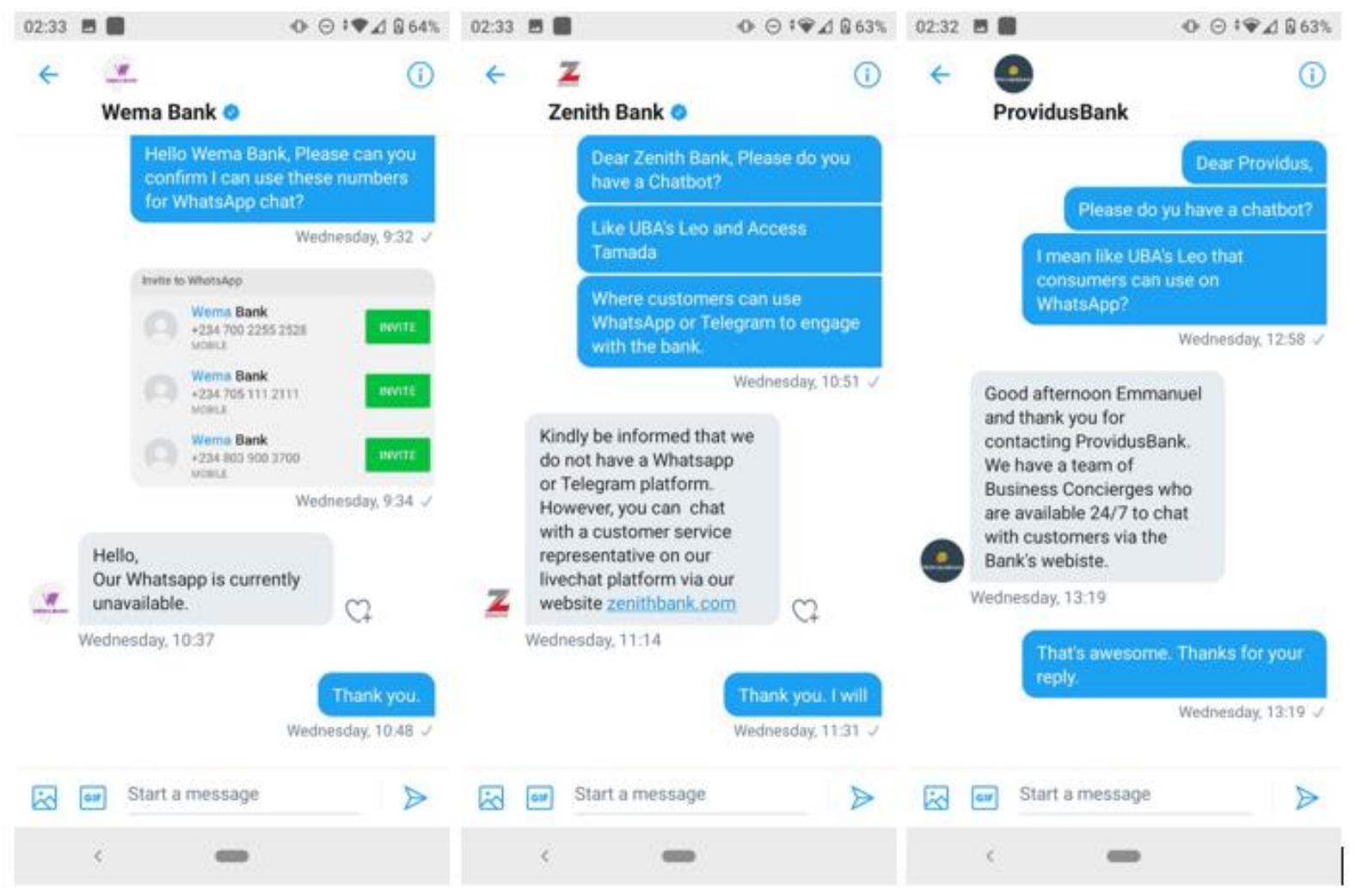

Figure 12: Message from Wema Bank, Zenith and Providus indicating they do not have Chatbots 